\title{
DESENVOLVIMENTO VEGETATIVO DA YACON SOB DIFERENTES ESPAÇAMENTOS DE PLANTIO
}

\author{
Magno do Carmo Parajara ${ }^{1}$ \\ Wallace Luís de Lima ${ }^{2}$ \\ Arnaldo Henrique de Oliveira Carvalho ${ }^{3}$ \\ Fábio Luiz de Oliveira ${ }^{4}$
}

Resumo: A Yacon, Smallanthus sonchifolius, tem apresentado inúmeros benefícios para a população, o que abre as expectativas sobre o seu cultivo como um produto a ser explorado. O objetivo do trabalho foi avaliar o desenvolvimento vegetativo da yacon em diferentes espaçamentos de plantio. O experimento foi conduzido na localidade Córrego Água Potável, no município de Ibatiba, ES. O delineamento utilizado foi em blocos ao acaso e os tratamentos foram os diferentes espaçamentos. As parcelas foram montadas num esquema de parcelas subdivididas, sendo as parcelas três espaçamentos entre linhas (EL), sendo EL1= $0,80 \mathrm{~m} ; E L 2=1,0 \mathrm{~m}$ e $E L 3=1,20$ metros, e as subparc elas três espaçamentos entre plantas $(E P)$, sendo $E P 1=0,40 \mathrm{~m} ; E P 2=0,50 \mathrm{~m}$ e $E P 3=0,60 \mathrm{~m}$,com 4 repetições. Verificou-se que as maiores alturas de plantas e diâmetros de caule foram observadas com espaçamento de 0,50 e 0,60 m entre plantas, sendo 42,66 cm e 13,40 mm, respectivamente. As plantas apresentaram baixo desenvolvimento vegetativo, bem inferior à encontrada em outros trabalhos, provavelmente ocasionado pelo deficit hídrico.

Palavras-chave: Smallanthus sonchifolius; Espaçamento; Desenvolvimento vegetativo.

\footnotetext{
${ }^{1}$ Graduando em Agronomia/Universidade Federal do Espírito Santo, Brasil. E-mail: magnocp1@hotmail.com.

2 Professor - Instituto Federal do Espírito Santo, Brasil. E-mail: wallace@ifes.edu.br.

${ }^{3}$ Professor - Instituto Federal do Espírito Santo, Brasil. E-mail: acarvalho@ifes.edu.br.

4 Professor - UFES - CCA, Departamento de Produção Vegetal, Brasil. E-mail: fabio.oliveira.2@ufes.br.
} 